\title{
Rabbit Serum Raised against $P$. aeruginosa Biofilm Exhibit Significant Biofilm Reduction and Removal Activity
}

\author{
Syed H. Abidi ${ }^{1,2^{*}}$, Khalid Ahmed ${ }^{1}$, Fatin Zehra ${ }^{3}$, Nouman Mughal ${ }^{3}$ and Shahana U. Kazmi ${ }^{2}$ \\ ${ }^{1}$ Department of Biological and Biomedical Sciences, Aga Khan University, Karachi-Pakistan \\ ${ }^{2}$ Immunology and Infectious Diseases Research Lab (IIDRL), Department of Microbiology, \\ University of Karachi, Karachi-Pakistan \\ ${ }^{3}$ Dow University of Health Sciences, Karachi-Pakistan \\ *Corresponding author
}

\begin{tabular}{|c|c|}
\hline \multirow{3}{*}{ Keywords } & A B S T R A C T \\
\hline & \multirow{9}{*}{$\begin{array}{l}P \text {. aeruginosa biofilms can offer resistance to antibiotics, and have evolved } \\
\text { mechanisms to evade innate and acquired immune systems. Biofilms infection } \\
\text { causes stimulation of innate and acquired immune systems. However, their } \\
\text { persistent activation may result in more immune-mediated tissue damage with } \\
\text { limited success in the removal of the biofilm pathogen. In this study we evaluated } \\
\text { the potential of the serum raised against } P \text {. aeruginosa biofilm antigen in reducing } \\
\text { and removing } P \text {. aeruginosa biofilms. We raised polyclonal sera in a Rabbit against } \\
P \text {. aeruginosa biofilm antigens. The efficacy of the antigen was tested using slide } \\
\text { agglutination test. We finally tested the efficacy of polyclonal sera to reduce and } \\
\text { remove biofilm formation. We found that the anti-sera from rabbit showed strong } \\
\text { immune response and disinfection activity against } P \text {. aeruginosa biofilm antigens. } \\
\text { Passive immunotherapies can be important in attenuating acute } P \text {. aeruginosa } \\
\text { infection and interfering with chronic infection. }\end{array}$} \\
\hline & \\
\hline Rabbit Serum & \\
\hline $\begin{array}{l}\text { Raised against } \\
\text { P. aeruginosa }\end{array}$ & \\
\hline Biofilm. & \\
\hline Article Info & \\
\hline $\begin{array}{l}\text { Accepted: } \\
\text { 12 June } 2016\end{array}$ & \\
\hline Available Online: & \\
\hline 10 July 2016 & \\
\hline
\end{tabular}

\section{Introduction}

$P$. aeruginosais known to cause catheterassociated urinary tract infections through biofilm formation on the surface of indwelling catheters (Cole et al., 2014; Mulcahy et al., 2013). These biofilms can offer resistance to antibiotics, and have evolved mechanisms to evade innate and acquired immune systems (Drenkard et al., 2002; Anderson et al., 2008).

Biofilms infection cause stimulation ofinnate and acquired immune systems
(Anderson et al., 2010). However, their persistent activation may result in more immune-mediated tissue damage with limited success in the removal of the biofilm pathogen (Kimbrell et al., 2001). The antibodies produced against $P$. aeruginosa virulence factors may also contribute to the host tissue damage.

Studies have documented the direct killing of gram-negative bacteria by serum, mediated by the Membrane Attach Complex which, employed after the activation of the 
complement system (Berends et al., 2015). We are interested to study the role of humoral immune response and evaluate the potential of the serum raised against $P$. aeruginosa biofilm antigen in reducing and removing $P$. aeruginosa biofilms. This may pave the way for vaccine development against pathogenic drug-resistant bacteria.

\section{Materials and Methods}

\section{Cultural conditions}

$P$. aeruginosa culture was inoculated in Tryptone Soy Broth for 24 hours at $37^{\circ} \mathrm{C}$. The next day,white matt at the air-liquid interface was pipetted out, transferred to saline tubes and vortexed for 1 minute to break the meshwork. Subsequently, $5 \mathrm{ml}$ formaline-saline was added and left overnight. Next morning, the cell suspension was centrifuged at 3000 RPM for 5 minutes. Supernatant was discarded and the pellet was washed twice and the pellet was suspended in 5-6 $\mathrm{ml}$ saline, and matched with 0.5 McFarland to obtain $10^{8}$ cells $/ \mathrm{ml}$. The content was innoculated on Nutrient Agar, Sabourauds dextrose Agar and Thioglycholate broth to check sterility.

\section{Sera against Pseudomonas aeruginosa}

To obtain the sera, $0.1,0.1,0.1,0.1,1,2$, and $2 \mathrm{ml}$ of antigen was administered into an adult, healthy rabbit at first, third, fifth, seventh, tenth, thirteenth, and twentieth day with, respectively, through intravenous route, except for the last two days for which intraperitoneal route was adapted. Two days after the last dose, the rabbit was heart bled. The blood was collected in sterile tubes; serum was separated and frozen at $-20^{\circ} \mathrm{C}$.

\section{Slide agglutination test}

Culture of P.aeruginosa was inoculated in Tryptone Soy Broth for 24 hours at $37^{\circ} \mathrm{C}$.
Next day, the white matt formed at the AirLiquid interface was pipette out and a drop of suspension was placed on a clean slide. A drop of rabbit serum was placed on a slide. Content of the slide was mixed and observed for clump formation. Agglutination occurring within five minutes was marked as strong response, while the delayed one was considered as weak response.

\section{Disinfection and Removal of Pseudomonas aeruginosa Biofilms}

Disinfection and removal of biofilm was determined in two ways as described previously (Abidi et al., 2014). In the first experiment, potential of the sera to inhibit $P$. aeruginosa biofilm formation was evaluated. For this, the culture was inoculated in 5-ml TSB and grown to stationary phase and diluted 1:100 in the Tryptone Soy Broth. $100 \mu \mathrm{l}$ of diluted culture was pipetted in 34 wells. $100 \mu$ of sera was inoculated in each well, and plate was covered and incubated at $37^{\circ} \mathrm{C}$ for 24 hours.

In the second experiment, potential of the sera to remove formed biofilms was evaluated. For this, microtitre plates were inoculated as mentioned above and incubated at $37{ }^{\circ} \mathrm{C}$ for 24 hours. After incubation plates were washed to remove planktonic cells. $200 \mu \mathrm{l}$ of rabbit serum was inoculated in each well and incubated for 1.5 hours.

Subsequently, four small trays were set up in a series and autoclaved tap water up was added in the last three, while first served as waste. Planktonic bacteria were removed from the microtiter plates by submerging the plates in water tray. For biofilm staining, 125 ulof $0.1 \%$ crystal violet solution was added to each well and incubated for $10 \mathrm{~min}$ at room temperature. Post-incubation, the stain was emptied over the waste tray and 
plates were washed successively in each of the next two water trays with vigorous shaking to remove all liquid. Subsequently, the plates were inverted and vigorously tapped on paper towels to remove all the contents and left to air dry. Finally, the dye was solubilized by adding $200 \mu \mathrm{l}$ of $95 \%$ ethanol and plates were covered and incubated for 10 to $15 \mathrm{~min}$ at room temperature. Next, contents of each well were mixed by repeated pipetting. $125 \mu \mathrm{l}$ of crystal violet-ethanol solution was transferred from each well to a separate well of a new optically clear flat-bottom 96-well plate. Optical densities (OD) of each of these 125- $\mu$ l samples were measured at a wavelength $630 \mathrm{~nm}$.

Measurement of anti-biofilm efficacy called Percentage Reduction was calculated from blank, control and test OD using equation:

Percentage Réduction $=((C-B)-(T-B) /(C-$ B))*100\%

Where $B=$ absorbance of blank, $C=$ absorbance of control and $T=$ absorbance of test.

\section{Results and Discussion}

\section{Slide Agglutination Test}

Pre-immunized rabbit sera showed agglutination within 5 minutes when incubated with $P$. aeruginosa biofilm content, indicating a strong response against biofilm proteins.

\section{Anti-biofilm Activity of Raised Sera against $P$. aeruginosa Biofilm}

Rabbit serum exhibited a46.16\% reduction in biofilm formation. Similarly, rabbit serum also displayed $54.7 \%$ reduction in preformed biofilms.

The present study found that the anti-sera from rabbit showed strong immune response against biofilm antigens. Our study supports the understanding that innate immunity may prove helpful in disruption of biofilm and allowing antibiotics to penetrate inside the inflammation (Ciofu, 2003).

Many studies have shown that the immune system may fail to eradicate $P$. aeruginosa biofilm (Mathee et al., 1999), especially in indwelling medical devices. Cases have been reported in which indwelling devices were removed and shown colonization by $P$. aeruginosa despite patients were being treated with antibiotics (Jesaitis et al., 2003). The antibody protective mechanism against biofilm by the host immunity may be mediated by Outer membrane protein (OMP). OMP belonging to the Omp85 family have been identified as antigen in pathogenesis and immunity against $P$. aeruginosa (Tashiro et al., 2008; Duchesne et al., 2013).It has been found that Opr86 acts as a protective antigen to inhibit biofilm formation by $P$. aeruginosa PAO1 and several other isolates. Furthermore, Pseudomonas aeruginosa OMPs have also been studied for potential vaccine antigens (Lee et al., 2000). OMPs have been found more suitable as antigens than lipopolysaccharides, exopolysaccharides, or isolated flagella for the clinical use.

The present study identifies a potential immunologic biofilm inhibition potential against clinical strains. Opr86 has also been proposed as a Pseudomonas aeruginosa would be a good target for design of both new antibiotics and vaccine (Tashiro et al., 2008).

In conclusion, in this study, we have demonstrated that the rabbit serum inhibited and removed P.aeruginosa biofilms. Therefore, passive immunotherapies that target this particular pathogen should be of 
value in attenuating acute infection and interfering with chronic infection.

\section{Acknowledgement}

We would like to thank Mr. Sikander K. Sherwani for the help he rendered towards experimental design. All consumables were obtained from Immunology and Infectious Diseases Research Laboratory.

\section{References}

Cole, S.J., Records, A.R., Orr, M.W., Linden, S.B., Lee, V.T. 2014. Catheter-associated urinary tract infection by Pseudomonas aeruginosa is mediated by exopolysaccharide independent biofilms. Infection and immunity. doi:10.1128/iai.01652-14

Mulcahy, L.R., Isabella, V.M., Lewis, K. 2013. Pseudomonas aeruginosa Biofilms in Disease. Microbial ecology. doi:10.1007/s00248-0130297-X

Drenkard, E., Ausubel, F.M. 2002. Pseudomonas biofilm formation and antibiotic resistance are linked to phenotypic variation. Nature, 416(6882): 740-743

Anderson, G., O'toole, G. 2008. Innate and induced resistance mechanisms of bacterial biofilms. In: Bacterial biofilms. Springer, pp 85-105.

Høiby, N., Krogh Johansen, H., Moser, C., Song, Z., Ciofu, O., Kharazmi, A. 2001. < i $>$ Pseudomonas aeruginosa $</ \mathrm{i}>$ and the in vitroand in vivo biofilm mode of growth. Microbes and Infec., 3(1): 23-35.

Cross, A., Allen, J.R., Burke, J., Ducel, G., Harris, A., John, J., Johnson, D., Lew, M., MacMillan, B., Meers, P., et al. 1983. Nosocomial infections due to Pseudomonas aeruginosa: review of recent trends. Rev. Infect. Dis., 5 Suppl 5: S837-845
Jensen, P.O., Givskov, M., Bjarnsholt, T., Moser, C. 2010. The immune system vs. Pseudomonas aeruginosa biofilms. FEMS immunology and medical microbiology $59 \quad$ (3):292-305. doi:10.1111/j.1574-695X.2010 $.00706 . x$

Kimbrell, D.A., Beutler, B. 2001. The evolution and genetics of innate immunity. Nature Reviews Genetics, 2(4): 256-267.

Berends, E.T., Mohan, S., Miellet, W.R., Ruyken, M., Rooijakkers, S.H. 2015. Contribution of the complement Membrane Attack Complex to the bactericidal activity of human serum. Mol. Immunol., 65(2): 328-335

Abidi, S.H., Ahmed, K., Sherwani, S.K., Bibi, N., Kazmi, S.U. 2014. Detection of Mycobacterium Smegmatis Biofilm and its Control by Natural Agents. Int. J. Curr. Microbiol. App. Sci., 3(4): 801-812.

Ciofu. O. 2003. Pseudomonas aeruginosa chromosomal beta-lactamase in patients with cystic fibrosis and chronic lung infection. Mechanism of antibiotic resistance and target of the humoral immune response. APMIS Supplementum, (116):1-47.

Mathee, K., Ciofu, O., Sternberg, C., Lindum, P.W., Campbell, J.I., Jensen, P., Johnsen, A.H., Givskov, M., Ohman, D.E., Søren, M. 1999. Mucoid conversion of Pseudomonas aeruginos by hydrogen peroxide: a mechanism for virulence activation in the cystic fibrosis lung. Microbiol., 145(6):13491357.

Jesaitis, A.J., Franklin, M.J., Berglund, D., Sasaki, M., Lord, C.I., Bleazard, J.B., Duffy, J.E., Beyenal, H., Lewandowski, Z. 2003. Compromised host defense on Pseudomonas aeruginosa biofilms: characterization 
of neutrophil and biofilm interactions. J. Immunol., 171(8): 4329-4339.

Tashiro, Y., Nomura, N., Nakao, R., Senpuku, H., Kariyama, R., Kumon, H., Kosono, S., Watanabe, H., Nakajima, T., Uchiyama, H. 2008. Opr86 is essential for viability and is a potential candidate for a protective antigen against biofilm formation by Pseudomonas aeruginosa. $J$. Bacteriol., 190(11): 3969-3978.

Duchesne, R., Bouffartigues, E., Oxaran, V., Maillot, O., Benard, M., Feuilloley, M.G., Orange, N., Chevalier, S. 2013.
A proteomic approach of SigX function in Pseudomonas aeruginosa outer membrane composition. Journal of proteomics 94:451-459. doi:10.1016/j.jprot.2013.10.022

Lee, N.G., Jung, S.B., Ahn, B.Y., Kim, Y.H., Kim, J.J., Kim, D.K., Kim, I.S., Yoon, S.M., Nam, S.W., Kim, H.S., Park, W.J. 2000. Immunization of burn-patients with a Pseudomonas aeruginosa outer membrane protein vaccine elicits antibodies with protective efficacy. Vaccine, 18(18): 1952-1961.

\section{How to cite this article:}

Syed H. Abidi, Khalid Ahmed, Fatin Zehra, Nouman Mughal and Shahana U. Kazmi. 2016. Rabbit Serum Raised against $P$. aeruginosa Biofilm Exhibit Significant Biofilm Reduction and Removal Activity. Int.J.Curr.Microbiol.App.Sci. 5(7): 275-279. doi: http://dx.doi.org/10.20546/ijcmas.2016.507.028 